\title{
Comparison of styrene removal in air by positive and negative DC corona discharges
}

\author{
X. Zhang $\cdot$ W. Feng $\cdot$ Z. Yu $\cdot$ S. Li $\cdot$ \\ J. Zhu $\cdot$ K. Yan
}

Received: 9 April 2012/Revised: 22 October 2012 / Accepted: 29 December 2012/Published online: 5 February 2013

(C) Islamic Azad University (IAU) 2013

\begin{abstract}
This communication discusses styrene removal in air by positive and negative DC corona discharges. Experiments were performed with a wire-plate reactor and under a gas flow rate of $305 \mathrm{~m}^{3} / \mathrm{h}$. In terms of averaged applied voltage and corona current, it is observed that the maximum negative corona current is always at least two times larger than the positive one at the same voltage level. At the same corona discharge energy density, however, the positive corona discharge produces around 2-6 times more ozone in comparison with the negative corona. For styrene removal, the positive corona processing is also around 2-6 times more effective than the negative corona. Humidity, an important and variable component of ambient air, affects the positive corona processing significantly. But it exerts a moderate effect on the negative corona. The differences between positive corona and negative corona discharges are attributed to their different discharge properties.
\end{abstract}

Keywords Corona discharge $\cdot$ Non-thermal plasma . Styrene $\cdot$ VOCs

Electronic supplementary material The online version of this article (doi:10.1007/s13762-012-0175-y) contains supplementary material, which is available to authorized users.

X. Zhang · W. Feng $\cdot$ Z. Yu $\cdot$ S. Li $\cdot$ J. Zhu $\cdot$ K. Yan (ه) Department of Chemical and Biological Engineering, Key Laboratory of Biomass Chemical Engineering of Ministry of Education, Zhejiang University, Hangzhou 310028, China e-mail: kyan@zju.edu.cn

\section{Introduction}

The emission of volatile organic compounds (VOCs) is a worldwide concern for human health and global warming. Today, in order to remove VOCs from air, many end-ofpipe technologies, such as thermal combustion, catalytic oxidation, carbon adsorption, condensation and non-thermal plasma (NTP), have been developed. Among these technologies, NTP, especially electrical discharge in air, can be an effective method when the VOCs exist as impurities, i.e., at low concentration (typically less than 500 ppm) (McAdams 2001; Yan et al. 2001a; Kim 2004; Lu et al. 2006; Yan et al. 2006; Zhu et al. 2008 and Gallon et al. 2011). In NTP, electrons are sufficiently energized to a temperature level of several $\mathrm{eV}$ (several $10,000 \mathrm{~K}$ ), whereas the background gases are still kept at room temperature level. The "hot" electrons collide with molecules of background gases, resulting in the generation of various chemical active species, such as energized electrons, ions, excited molecules, atoms and radicals, which are useful for VOC removal.

Depending on the NTP generation methods and reacting species (e.g., VOC compounds), different active species may prevail in the reaction, which result in different removal characteristics (Chang et al. 1991; Penetrante et al. 1997; Yao et al. 2001; Nair et al. 2004; Tu et al. 2011; Vandenbroucke et al. 2011). Reacting species influence removal efficiency and removal pathway (e.g., product and kinetic) (Mok et al. 2008; Zhu et al. 2009; Fan et al. 2011). Until now, more than 50 kinds of VOCs have been investigated in different plasma reactors for their emission control. For styrene, an important synthetic chemical that is often emitted in the plastic, rubber and resin industry [in US, the threshold limit value of styrene in the workplace is $20 \mathrm{ppm}$ (Styrene information \& research center, 
http://www.styrene.org/regulatory/osha_regulation.html)], a few reports are available (Anderson et al. 1999; Tanthapanichakoon et al. 2004; Chang et al. 2005). Recently, Zhang et al. (2011) reported that styrene shows zero-order removal kinetics in an AC/DC streamer corona reactor. This zero-order removal kinetics is different from previous reports on other clean hydrocarbons where the removal kinetics are first-order ones. With regard to plasma generation method, it mainly influences energy efficiency (Marotta et al. 2008). Considering cost-performance ratio, DC corona discharges are superior to other NTP generation techniques (Hensel et al. 2005; Durme et al. 2007a, b). Several works have reported that DC corona processing efficiency is different when using different discharge polarities. Cooray and Rahman (2005) found that positive corona is more efficient than negative corona for NOx and $\mathrm{O}_{3}$ production from air discharge. Wan et al. (2011) studied formaldehyde removal by DC corona discharges. They reported that positive polarity discharge is much more effective than the negative one. While some studies showed that positive corona discharge is superior to the negative one, other studies found opposite results (Yehia et al. 2000; Marotta et al. 2008; Schiorlin et al. 2009). It is still necessary to study the effect of discharge polarities on VOC removal efficiency.

This communication compares styrene removal in air using positive and negative DC corona discharges. The experiments are carried out under various humidity conditions since ambient air usually contains variable amounts of water. The obtained results are discussed to explain the effect of discharge polarities on styrene removal efficiency. This work is part of an ongoing project toward better understanding of fundamental and system design of NTP for styrene emission control. It was carried out in Zhejiang Province of China in 2011.

\section{Materials and methods}

Details of experimental setup and experimental procedure were early reported (Zhang et al. 2010, 2011). In brief, the corona plasma is generated in a wire-plate type reactor with effective volume of $144.5 \mathrm{~L}$ (850 mm in length $\times 850 \mathrm{~mm}$ in height $\times 200 \mathrm{~mm}$ in width). There are 16 stainless steel saw-type electrodes fixed at the middle of two grounded plates as high-voltage electrodes. The reactor is installed in a closed-loop flow system, which has $780 \mathrm{~L}$ of total gas volume and $305 \mathrm{~m}^{3} / \mathrm{h}$ of air circulation flow rate. As a result, the circulation time is about $9.3 \mathrm{~s}$. The DC power source has following features: input voltage $0-220 \mathrm{~V}$, output voltage -40 to $+35 \mathrm{kV}$, output current $0-10 \mathrm{~mA}$.

Before performing corona processing, the air temperature $(285-288 \mathrm{~K})$ and the relative humidity $(\mathrm{RH})$ inside the system are recorded by using a thermo-humidity meter (DT-615, Cem Co., Ltd.). For carrying out each experiment on styrene removal, a given amount of aqueous styrene (chemical pure, Linfeng Co., Ltd.) is injected into the closed-loop flow system. At the same time, the circulation fan is turned on for a sufficient time to get a stable styrene concentration inside the system. DC corona plasma is then applied for removing styrene.

A gas chromatogram (GC9750, Fuli Co., Ltd.) is used for quantitatively monitoring styrene concentration. Ozone concentration is recorded by using an ozone detector (Fig. 1). This detector consists of an UV light source (D100, Saifan Co., Ltd.), a spectrometer (HR2000+, Ocean Optics Co., Ltd.), two laboratory-grade solarization-resistant optical fibers (400 $\mu \mathrm{m}$, Ocean Optics Co., Ltd.) and two collimating quartz lenses (homemade). The spectrometer is used

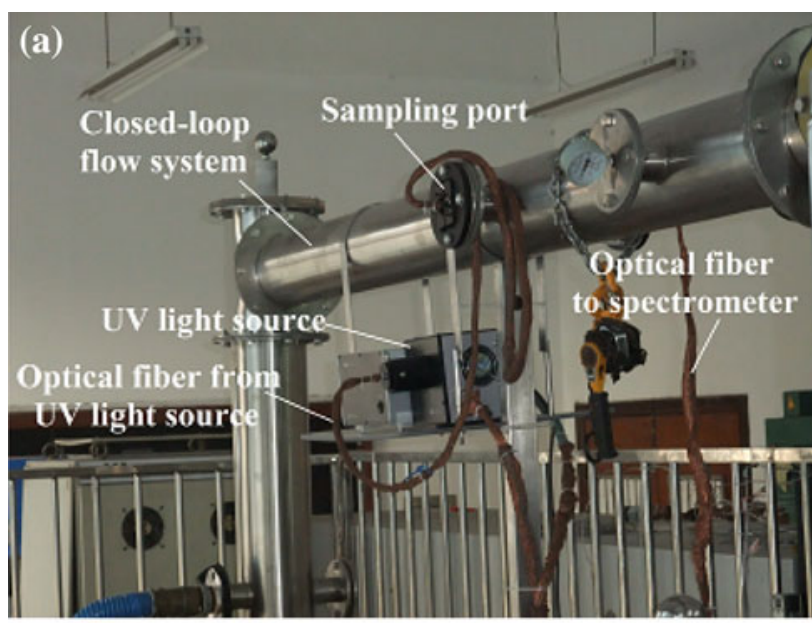

(b)

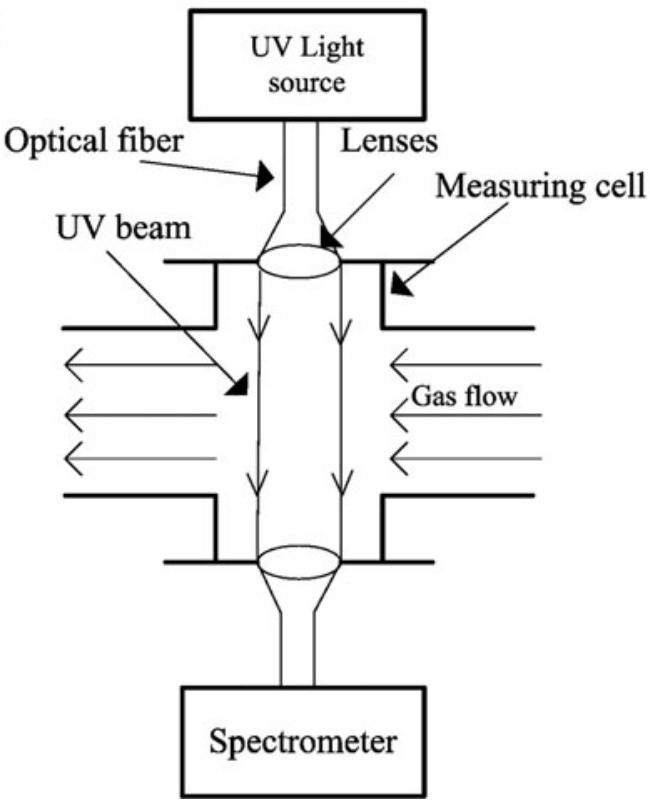

Fig. 1 UV absorption technique setup: a picture, b schematic overview 
for acquiring the spectrum. The optical fibers are used for optical connection between the UV light source and spectrometer. The collimating quartz lenses are used for focusing the UV light inside the measuring cell $(0.15 \mathrm{~m})$, which is located in the sampling port of the closed-loop flow system. The background spectrum (without ozone) and absorption spectrum are recorded at the wavelength of $254 \mathrm{~nm}$ before and after corona discharge, respectively. The ozone concentration is determined by using LambertBeer's law. Each spectrum for calculating ozone concentration is an average of at least seven repeats.

The electrical measurement system includes: a highvoltage probe (P 150G, Finechem Co., Ltd.), a current sensor (TCP 202, Tektronix Co., Ltd.) for measuring time-resolved current waveform, a current meter (C-31, Liangbiao Co., Ltd.) for measuring mean corona current, and a four-channel digital oscilloscope (DPO 7054, Tektronix Co., Ltd.). The corona discharge energy density $(\mathrm{J} / \mathrm{L})$ is expressed as the energy required per volume of the treated gas.

\section{Results and discussion}

Figure 2 shows the result of voltage-current $(V-I)$ characteristics under various atmosphere conditions. The maximum negative corona current is always at least two times larger than positive one at a same voltage level. For negative polarity, $V-I$ characteristics are insensitive to the varying of atmosphere conditions (Fig. 2a). In contrast, in analogous experiments with positive one (Fig. 2b), a pronounced decrease of corona current is observed in the conditions of high-humidity air and styrene-containing air.

Figure 3 shows the styrene removal efficiency as functions of energy density. Positive corona discharge is about 2-6 times more effective than negative one. When changing RH values from 40 to $71 \%$, removal efficiency decreases significantly in positive corona processing. In negative corona processing, however, the effect of RH value is moderate. A slight increase in efficiency is found at a high RH value.

Further studies are carried out on ozone production in air due to two reasons: (1) ozone concentration links to $\mathrm{O}$ atoms productivity, (2) ozone contributes to styrene removal due to its high chemical activity towards styrene molecules (Zhang et al. 2011). Similar to the styrene removal, a high humidity exerts a negative effect on ozone generation (Fig. 4). Positive corona discharge is around 2-6 times more efficient than negative corona discharge when experimental conditions are similar. The effect of $\mathrm{RH}$ value on ozone production is more significant in the positive corona discharge than in the negative one.

Based on the above results, some important specifications regarding the system design of DC corona discharges are summarized in supply material (Table 1).
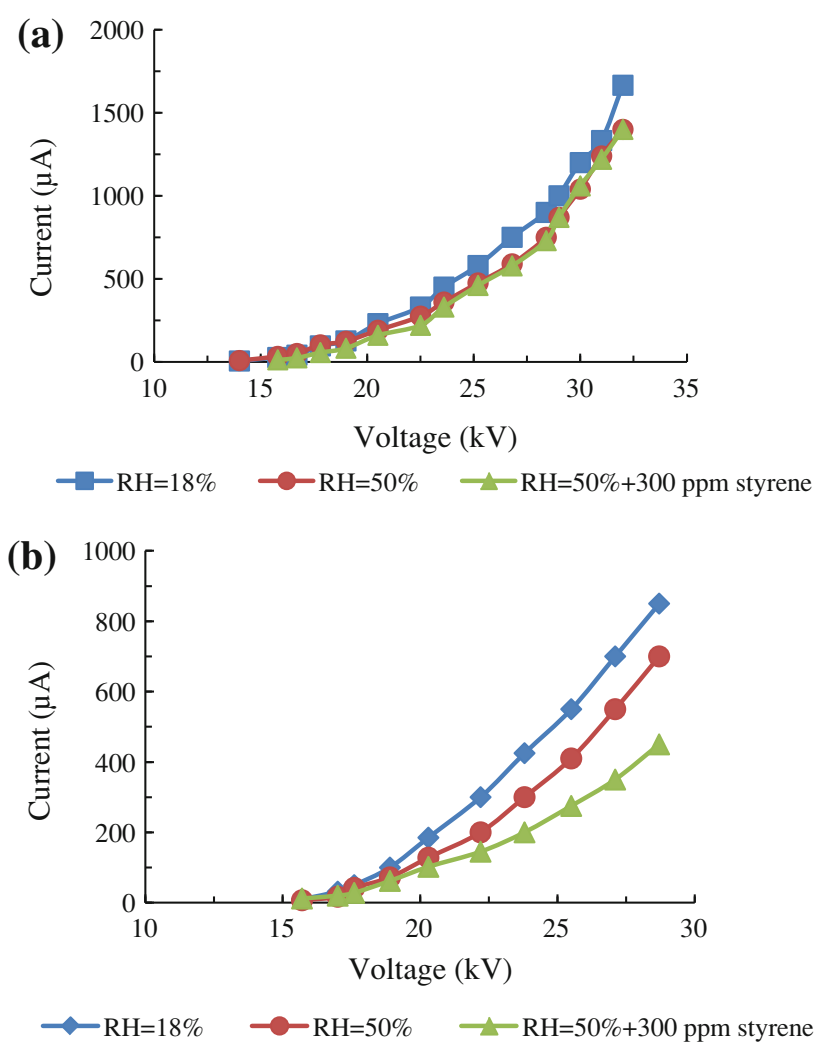

Fig. $2 V-I$ characteristics under different atmosphere conditions: a negative corona discharge, $\mathbf{b}$ positive corona discharge

The above results have shown that positive and negative DC corona discharges exert different effects on styrene removal in air. It is believed that this difference is a result of their different discharge properties. It is known that when using a saw-type high-voltage electrode, negative DC corona discharge always appears as a Trichel pulse shape in air (Chang et al. 1991). The negative streamers emit randomly from high-voltage electrodes with a repetition frequency of $10-100 \mathrm{kHz}$. But the discharge volume is restricted to a narrow region around the electrodes because of the opposite direction of streamers and space charges. The reactor space is dominated by ion drift region rather than plasma, thus initiating insignificant chemical reaction. With regard to positive DC corona discharge, however, there are two modes: streamer and glow. These two modes can be distinguished by investigating their time-resolved current waveform (see Supply material Fig. 1 as an example). Similar to the negative corona discharge, the positive glow discharge can only be found in the vicinity of the highvoltage electrode. Therefore, the chemical effectiveness is insignificant (Yan et al. 2001b). In contrast, the positive streamer discharge shows a higher processing efficiency because of its large plasma volume (Yan et al. 2001b). In the present study, the positive DC corona is classified 

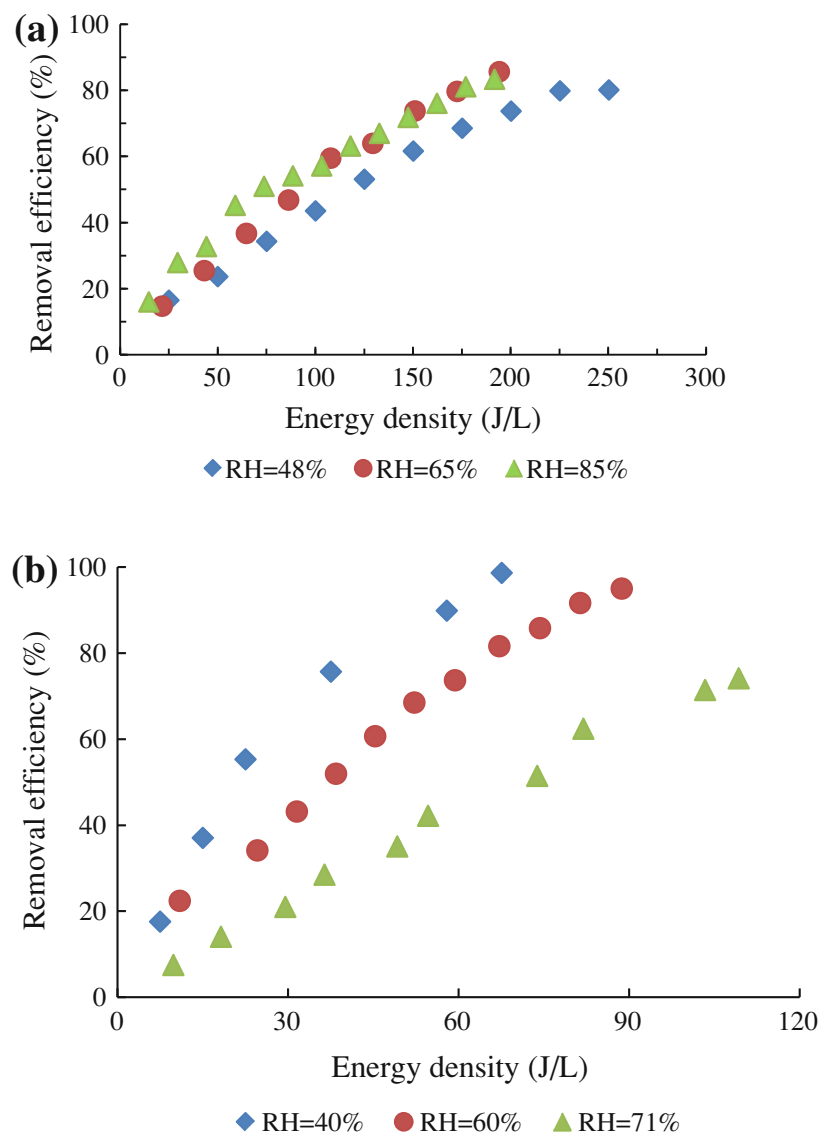

Fig. 3 Styrene removal efficiency as functions of energy density under various humidity conditions: a negative corona discharge $\left(C_{0}=60-70 \mathrm{ppm}\right), \quad \mathbf{b}$ positive corona discharge $\left(C_{0}=100-\right.$ $110 \mathrm{ppm})$

as streamer discharge mode by considering its current waveform (see Supply material Fig. 1b). As a result, the positive polarity discharge is more efficient than the negative one.

The response of DC corona current to humidity in air discharge has been reported and discussed by Marotta et al. (2008). In positive polarity discharge, a pronounced decrease of corona current in high-humidity conditions is attributed to the generation of heavy water ion clusters. In negative discharge, however, the ions generated from water containing air are almost as heavy as those ions generated from dry air. Therefore, the corona current is insensitive to the varying humidity.

The decrease of corona current at the conditions of VOCs containing air was also reported by Schiorlin et al. (2009), who studied the toluene removal using a positive DC corona discharge. Moreover, they observed that the toluene removal efficiency is insensitive to the varying of $\mathrm{RH}$ values. They attributed these results to the reaction of toluene with positive ions (e.g., $\mathrm{O}_{2}{ }^{+}, \mathrm{H}_{3} \mathrm{O}^{+}$). The toluenederived positive ions thus generated are heavier than those
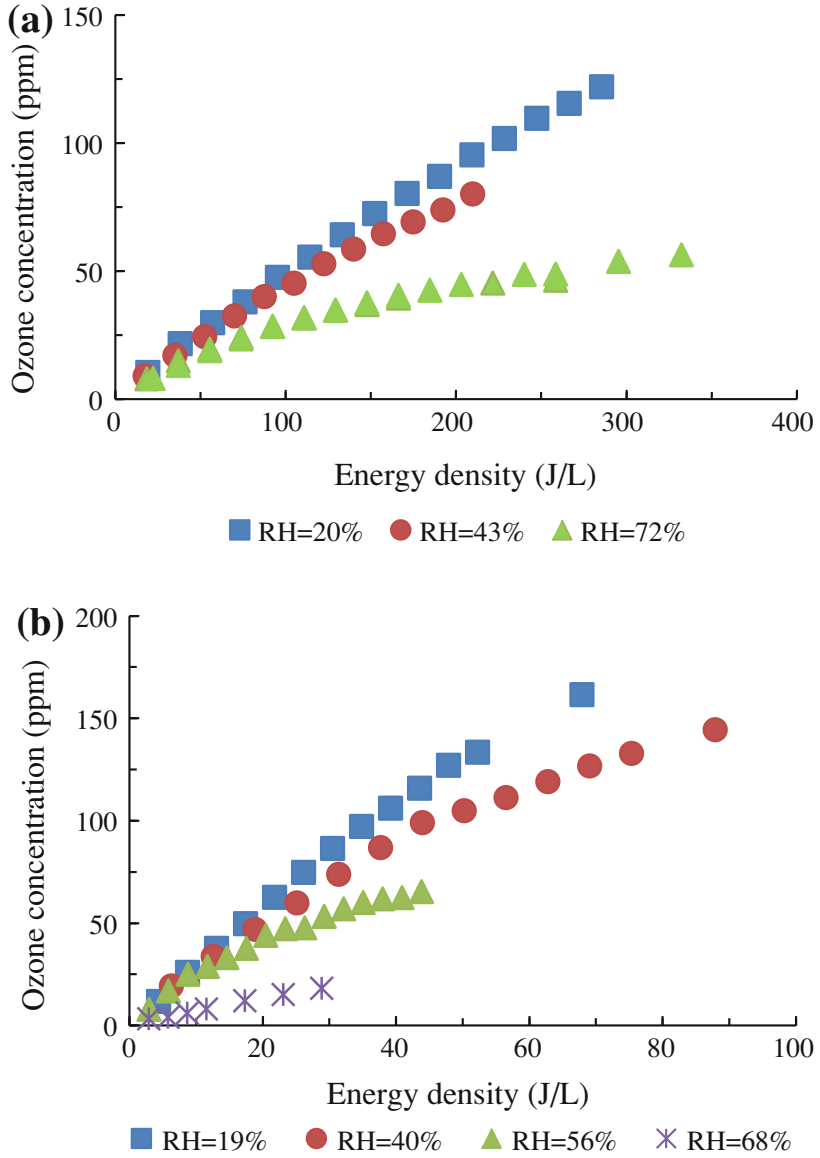

Fig. 4 Ozone concentration as functions of energy density under various humidity conditions: a negative corona discharge, b positive corona discharge

ions generated from air discharge, and resulting into the decrease of corona current. In the present study, the styrene-derived positive ions may also be generated in the positive corona discharge as styrene has higher chemical reactivity than toluene. This argument is also in agreement with the experimental result that a pronounce decrease in corona current is found in the styrene-containing air. But, it should be noted that the positive corona discharge in reference (Schiorlin et al. 2009) was operated in the glow mode. In this study, however, the positive corona discharge is operated in the streamer mode. Even if the styrenederived positive ions are generated, it does not mean that the styrene removal is dominated by ionic reaction. Previous study has shown that positive streamer corona induced styrene removal is dominated by radicals/atoms reaction (Zhang et al. 2011). The decrease in removal efficiency at a high humidity condition can be attributed to the quenching of $\mathrm{O}$ atoms and $\mathrm{OH}$ radicals by water vapors and $\mathrm{OH}$ radicals, respectively (Zhang et al. 2011).

With regard to the negative corona processing, the main reaction pathways for VOCs removal are also related to the 
radicals/atoms initiated reactions (Schiorlin et al. 2009). However, ion chemistry (e.g., reactions initialed by $\mathrm{O}^{-}$, $\mathrm{O}_{3}{ }^{-}$and $\mathrm{OH}^{-}$) may involve in the styrene removal reaction in some extent by considering two reasons: (1) reactor space is dominated by ion drift region, (2) in contrast to the positive processing, the effect of humidity on the styrene removal efficiency, ozone production and $V-I$ characteristic are moderate.

Further works should focus on studying ions and atoms/radicals behavior, including detection of ions and atoms/radicals species, and discussion of ion-styrene and atom/radical-styrene reactions. Moreover, removal products from corona processing should also be studied.

\section{Conclusion}

Styrene removal in air by positive and negative DC corona discharges has been compared. In terms of averaged applied voltage and corona current, it is observed that the maximum negative corona current is always larger than positive one at a same voltage level. For ozone production and styrene removal, however, positive corona discharge is more efficient than negative corona discharge. Humidity, an important and variable component of ambient air, affects the positive corona processing significantly. But it exerts a moderate effect on the negative corona processing. All of above results indicates that negative and positive corona discharges have very different chemical effectiveness. These differences are attributed to their different discharge properties. Further investigations on ions related chemical reactions and byproducts analysis will help to get a deep insight on positive and negative corona induced chemical processes.

Acknowledgments This work is supported financially by the Natural Science Foundation of China (NSFC-N10711), China Postdoctoral Science Foundation (No.X90906), National High Technology Research and Development Program of China (863 Program) (No.SS2013AA0616), and the fundamental research funds for the central universities 2012XZZX001.

\section{References}

Anderson GK, Snyder H, Coogan J (1999) Oxidation of styrene in a silent discharge. Plasma Chem Plasma Process 19(1):131-151

Chang JS, Lawless A, Yamamoto T (1991) Corona discharge processes. IEEE Trans Plasma Sci 19(6):1152-1166

Chang CL, Bai H, Lu SJ (2005) Destruction of styrene in an air stream by packed dielectric barrier discharge reactors. Plasma Chem Plasma Process 25(6):641-657
Cooray V, Rahman M (2005) Efficiencies for production of $\mathrm{NO}_{\mathrm{x}}$ and $\mathrm{O}_{3}$ by streamer discharges in air at atmospheric pressure. J Electrostat 63:977-983

Durme JV, Dewulf J, Sysmans W, Leys C, Langenhove HV (2007a) Abatement and degradation pathways of toluene in indoor air by positive corona discharge. Chemosphere 68(10):1821-1829

Durme JV, Dewulf J, Sysmans W, Leys C, Langenhove HV (2007b) Efficient toluene abatement in indoor air by a plasma catalytic hybrid system. Appl Catal B Environ 74(1-2):161-169

Fan X, Zhu T, Sun Y, Yan X (2011) The roles of various plasma species in the plasma and plasma-catalytic removal of lowconcentration formaldehyde in air. J Hazard Mater 196:380-385

Gallon HJ, Tu X, Twigg MV, Whitehead JC (2011) Plasma-assisted methane reduction of a $\mathrm{NiO}$ catalyst-low temperature activation of methane and formation of carbon nanofibres. Appl Catal B Environ 106(3-4):616-620

Hensel K, Katsura S, Mizuno A (2005) DC micro discharges inside porous ceramics. IEEE Trans Plasma Sci 33(2):574-575

Kim HH (2004) Non-thermal plasma processing for air-pollution control: a historical review, current issues, and future prospects. Plasma Process Polym 1(2):91-110

Lu B, Zhang X, Yu X, Feng T, Yao S (2006) Catalytic oxidation of benzene using DBD corona discharges. J Hazard Mater B137(1): 633-637

Marotta E, Callea A, Ren X, Rea M, Paradisi C (2008) DC Corona electric discharges for air pollution control, 2-ionic intermediates and mechanisms of hydrocarbon processing. Plasma Process Polym 5(2):146-154

McAdams R (2001) Prospects for non-thermal atmospheric plasmas for pollution abatement. J Phys D Appl Phys 34(18):2810-2821

Mok YS, Demidyuk V, Whitehead JC (2008) Decomposition of hydrofluorocarbons in a dielectric-packed plasma reactor. J Phys Chem A 112(29):6386-6591

Nair SA, Yan K, Pemen AJM, van Heesch EJM, Drinkenburg AAH (2004) Tar removal from biomass-derived fuel gas by pulsed corona discharges: a chemical kinetic study. Ind Eng Chem Res 43(7):1649-1658

Penetrante BM, Hsiao MC, Bardsley JN, Merritt BT, Vogtlin GE, Wallman PH, Kuthi A, Burkhart CP, Bayless JR (1997) Identification of mechanisms for decomposition of air pollutants by non-thermal plasma processing. Plasma Sources Sci Technol 6:251-259

Schiorlin M, Marotta E, Rea M, Paradisi C (2009) Comparison of toluene removal in air at atmospheric conditions by different corona discharges. Environ Sci Technol 43(24):9386-9392

Tanthapanichakoon W, Charinpanitkul T, Chaiyo S, Dhattavorn N, Chaichanawong J, Sano N, Tamon H (2004) Effect of oxygen and water vapor on the removal of styrene and ammonia from nitrogen by non-pulse corona-discharge at elevated temperatures. Chem Eng J 97(2-3):213-223

Tu X, Verheyde B, Corthals S, Paulussen S, Sels BF (2011) Effect of packing solid material on characteristics of helium dielectric barrier discharge at atmospheric pressure. Phys Plasmas 18(8): $0807021-4$

Vandenbroucke AM, Morent RN, Geyter D, Leys C (2011) Nonthermal plasmas for non-catalytic and catalytic VOC abatement. J Hazard Mater 195(15):30-54

Wan Y, Fan X, Zhu T (2011) Removal of low-concentration formaldehyde in air by DC corona discharge plasma. Chem Eng J 171(1):314-319

Yan K, Heesch EJM, Pemen AJM, Huijbrechts PAHJ (2001a) From chemical kinetics to streamer corona reactor and voltage pulse generator. Plasma Chem Plasma Process 21(1):107-137 
Yan K, Yamamoto T, Kanazawa S, Ohkubo T, Nomoto Y, Chang JS (2001b) NO removal characteristics of a corona radical shower system under DC and AC/DC superimposed operations. IEEE Trans Ind Appl 37(5):1449-1504

Yan NQ, Qu ZJ, Jia P, Wang XP, Wu D (2006) Removal characteristics of gaseous sulfur-containing compounds by pulsed corona plasma. Ind Eng Chem Res 45(19):6420-6427

Yao S, Nakayama A, Suzuki E (2001) Methane conversion using a high-frequency pulsed plasma: discharge features. AIChE J 47(2):419-426

Yehia A, Abdel-Salam M, Mizuno A (2000) On assessment of ozone generation in DC coronas. J Phys D Appl Phys 33:831-835

Zhang X, Chen W, Zhu J, Feng W, Yan K (2010) Aerosol formation and decomposition of benzene derivatives by AC/DC streamer corona discharge. 7th International Symposium. Non-Thermal Plasma Technol. (ISNTP-7), Special Issue of Int J Plasma Environ Sci Technol 4 (2):130-134

Zhang X, Zhu J, Li X, Liu Z, Ren X, Yan K (2011) Characteristics of styrene removal with an AC/DC streamer corona plasma system. IEEE Trans Plasma Sci 39(6):1481-1488

Zhu T, Li J, Jin Y, Liang Y, Ma G (2008) Decomposition of benzene by non-thermal plasma processing: Photocatalyst and ozone effect. Int J Environ Sci Tech 5(3):375-384

Zhu T, Li J, Jin YQ, Liang YH, Ma GD (2009) Gaseous phase benzene decomposition by non-thermal plasma coupled with nano Titania catalyst. Int J Environ Sci Tech 6(1):141-148 